\title{
Kinetic modelling of the solid-liquid extraction process of polyphenolic compounds from apple pomace: influence of solvent composition and temperature
}

Parinaz Hobbi ${ }^{1}$, Oseweuba Valentine Okoro ${ }^{1}$, Christine Delporte ${ }^{2}$, Houman Alimoradi $^{3}$, Daria Podstawczyk ${ }^{4}$, Lei $\mathrm{Nie}^{5}$, Katrien V. Bernaerts ${ }^{6}$ and Amin Shavandi ${ }^{*}$ (i)

\begin{abstract}
This study aims to assess kinetic modelling of the solid-liquid extraction process of total polyphenolic compounds (TPC) from apple pomace (AP). In this regard, we investigated the effects of temperature and solvent (i.e. water, ethanol, and acetone) on TPC extraction over various periods. The highest TPC yield of $11.1 \pm 0.49 \mathrm{mg}$ gallic acid equivalent (GAE)/g db (dry basis) was achieved with a mixture of $65 \%$ acetone- $35 \%$ water $(\mathrm{v} / \mathrm{v})$ at $60^{\circ} \mathrm{C}$. The kinetics of the solvent-based TPC extraction processes were assessed via first-order and second-order kinetic models, with an associated investigation of the kinetic parameters and rate constants, saturation concentrations, and activation energies. The second-order kinetic model was sufficient to describe the extraction mechanism of TPC from AP. This study provides an understanding of the mass transfer mechanism involved in the polyphenolic compound extraction process, thus facilitating future large-scale design, optimization, and process control to valorize pomace waste.
\end{abstract}

Keywords: Apple pomace, Polyphenolic compounds, First-order kinetic model, Second-order kinetic model, Waste valorization, Value extraction

\footnotetext{
*Correspondence: Amin.Shavandi@ulb.be

1 Université Libre de Bruxelles (ULB), École polytechnique de Bruxelles - BioMatter unit, Avenue F.D. Roosevelt, 50 - CP 165/61, 1050 Brussels, Belgium

Full list of author information is available at the end of the article
} original author(s) and the source, provide a link to the Creative Commons licence, and indicate if changes were made. The images or other third party material in this article are included in the article's Creative Commons licence, unless indicated otherwise in a credit line to the material. If material is not included in the article's Creative Commons licence and your intended use is not permitted by statutory regulation or exceeds the permitted use, you will need to obtain permission directly from the copyright holder. To view a copy of this licence, visit http://creativecommons.org/licenses/by/4.0/. 


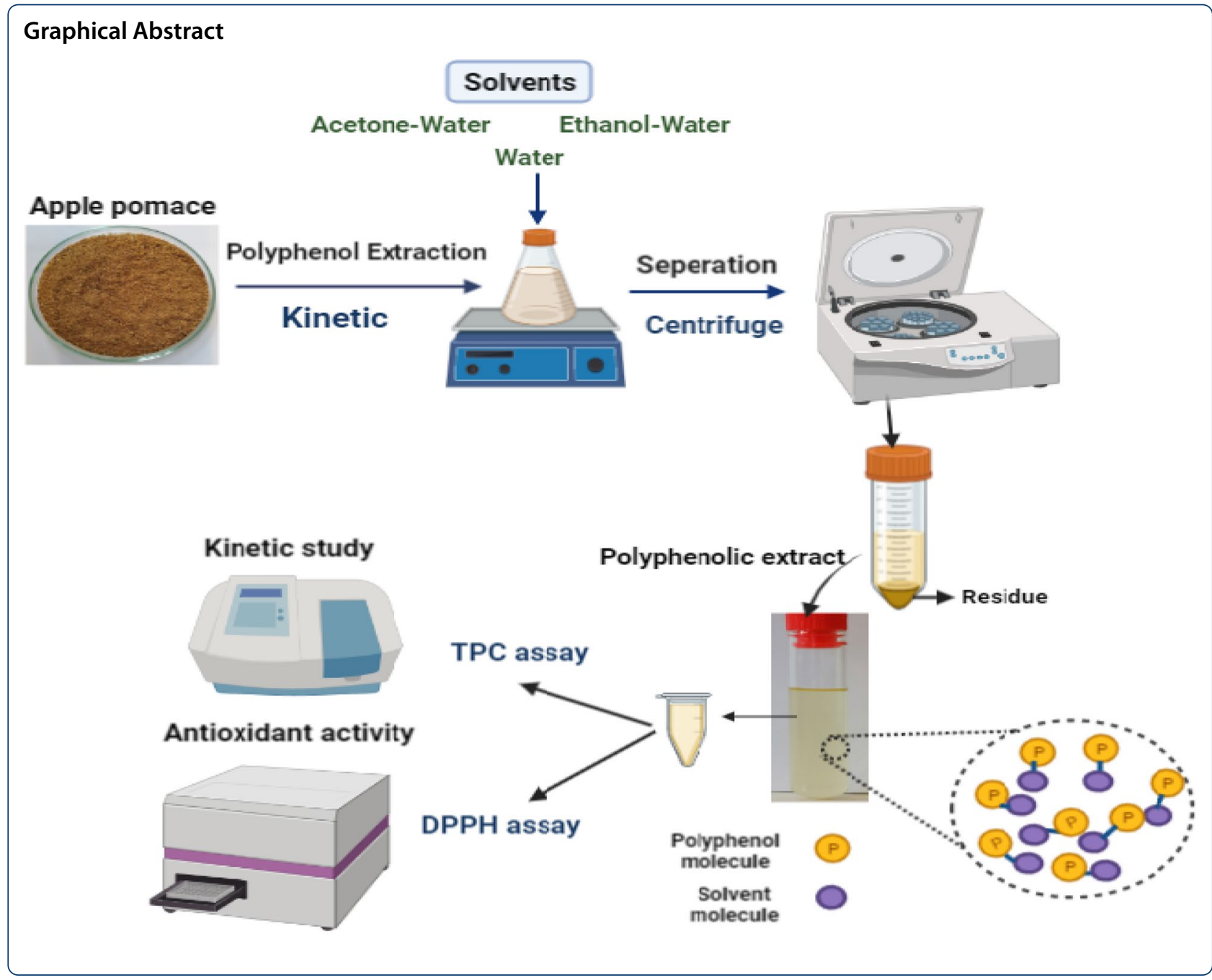

\section{Introduction}

Apple pomace (AP) is the main residue obtained from the apple processing industries of wine, jam, juice, cider and constitutes $25-30 \%$ of the mass of processed apple (Antonic et al. 2020). About 10 million tonnes of AP are generated globally every year (Alongi et al. 2019). One of the most common approaches for disposing of this by-product is through direct discarding to the soil in a landfill causing environmental pollution (Bhushan et al. 2008). Indeed, once applied to fields, AP, characterized by high moisture content (70-75\%) and high biodegradability, encounters microbial decomposition leading to greenhouse gas (GHG) emission (Bhushan et al. 2008; Okoro et al. 2021).

In the context of environmental management and the circular paradigm (Okoro et al. 2017), recycling AP is of great interest due to the presence of various compounds, such as polysaccharides, dietary fibres, minerals, and bioactive polyphenolic compounds which can be utilized for the production of a wide range of highvalue compounds (Lyu et al. 2020a). AP is a mixture of skin and flesh (95 wt.\%), seeds (2-4wt.\%), and stems (1 wt.\%) (Perussello et al. 2017), which contain different polyphenolic compounds such as epicatechin, quercetin, phloretin, chlorogenic acid, protocatechuic acid, caffeic acid, p-coumaric acid, ferulic acid, salicylic acid, phloridzin, and 3-hydroxyphloridzin (Antonic et al. 2020; Lyu et al. 2020a). The antioxidant, anti-inflammatory, anti-cancer, and anti-diabetic properties of some of these polyphenolic compounds are well-characterized (Shavandi et al. 2018). Moreover, in recent years, their applications in biomaterial engineering for the stimulation of bone formation and remineralization, fabrication of anti-diabetic wound healing scaffolds have also attracted considerable attention (Shavandi et al. 2018). Given the abundance of AP and complications of current disposal methods, there has been an increasing interest in value extraction from this organic 
waste stream, particularly as a sustainable source of useful polyphenolic compounds.

Among various extraction methods used for the recovery of polyphenolics from organics such as solid-liquid extraction, microwave-assisted extraction, pressurized liquid extraction, ultrasonic, electric field assisted extraction and supercritical fluid extraction (Perussello et al. 2017), solid-liquid extraction using solvents such as ethanol, methanol, acetone, and their mixtures with water constitute the most widely used extraction techniques (Li et al. 2020). These solvents are characterized by high extraction efficiencies in the recovery of wide ranges of polyphenols with different structures and are cheaper compared to other methods. Moreover, the application of optimization process in soild-liquid extraction provides a suitable extraction rate and yield (Li et al. 2020; Perussello et al. 2017). For instance, a step-wise fractionation method for the extraction of polyphenolic compounds from AP using water at room temperature and subsequent extractions using methanol and then acetone was investigated by Reis et al. (2012). Their study confirmed the efficiency of water and aqueous methanol and acetone solvents for the extraction of water-soluble and organic solvent-soluble polyphenolic compounds with significant antioxidant activity. In the same study, water was suggested as a potential solvent for the extraction of different kinds of polyphenolic compounds from AP which is environmentally friendly and cheap. To maximize the yield of extracted polyphenolic compounds from AP, several studies have been carried out to optimize experimental extraction conditions. For instance, Zardo et al. (2020) utilized acetone, ethanol, and methanol to enhance the extraction of polyphenolic compounds from AP by investigating the effect of particle size, ratio of AP to solvent, and solvent concentration on the total polyphenolic compound (TPC) yields. The use of different solvents may result in the recovery of different types and concentrations of TPC. For instance in the study by Wijngaard and Brunton (2010), the extraction of polyphenolic compounds by acetone and ethanol was optimized and TPC value of $1415 \mathrm{mg} \mathrm{GAE} / 100$ dry basis (db) and $1092 \mathrm{mg}$ GAE/100 db was achieved, respectively. The results of this study demonstrated that these two solvents could be preferentially employed when compared with methanol to facilitate polyphenolic extraction. In addition, acetone and ethanol are considered more environmental friendly solvents than methanol (Wijngaard and Brunton 2010).

Mathematical modelling has been considered as an important step in process engineering such as extraction processes due to the fact that the influence of process parameters on the outcome of the process is quickly determined with minimizing the number of needed experiments. Solid-liquid extraction is a heterogeneous, multicomponent process in which the mass transfer mechanism from solid to liquid happens at different rates. Application of kinetic model and analyses of model parameters provides a good realization of the extraction mechanism (Bucic-Kojic et al. 2013). Despite the importance of TPC extraction kinetics in optimization of the methods, this has not been adequately studied so far.

The kinetic modelling of TPC extraction plays a key role in the scaling-up the process for industrial applications. Furthermore, given that temperature and extraction time are considered as the two main parameters that may influence the efficiency of TPC extraction, undertaking kinetic modelling of the extraction process is necessary to aid future process design via reducing energy, time and chemical reagent consumption (Jurinjak Tušek et al. 2016; Shewale and Rathod 2018). In a study (Lazar et al. 2016), the second-order kinetic model was successfully applied to describe the mechanism of the ultrasound-assisted extraction of polyphenols from spruce bark (Picea abies), in which ultrasound and temperature provided significant effect on extraction yield and kinetics of the polyphenols extraction. Another study (Qu et al. 2010) also successfully developed a second-order kinetic model for describing the extraction process of polyphenols compounds from pomegranate marc under different extraction parameters, such as temperature, particle size and solid/solvent ratio.

First-order kinetic model was applied for the conventional and ultrasound-assisted extractions of polyphenol from AP and comparing the obtained kinetic parameter (K) showed that both extraction methods followed the same first-order kinetic models (Pingret et al. 2012). However, to the best of our knowledge no more studies have been carried out on kinetic modelling of polyphenol extraction from AP. This study, therefore, is designed to investigate the kinetics of TPC extraction from AP influenced by temperature and solvent composition and determine the best-fitting kinetic model for the extraction process. Given that the firstand second-order kinetic models are commonly used to investigate adsorption, desorption and extraction processes, we applied these models under the non-equilibrium conditions to model the solid-liquid extraction process of polyphenolic compounds from AP. The effect of three environmentally benign solvents, i.e. water, ethanol, and acetone, were assessed in terms of the yield of the TPC extracted and the associated kinetic parameters of extraction rate constants, saturation concentrations, and activation energies. 


\section{Materials and methods Materials}

Apple pomace containing apple flesh, skin, seeds, and stems were acquired from Materne-Confilux Company (Namur, Belgium). The samples were well mixed to achieve homogeneity. The acquired samples were subsequently dried in an oven to constant mass at a temperature of $60{ }^{\circ} \mathrm{C}$ for $24 \mathrm{~h}$. The dried apple sample was ground to a fine powder and sieved using 0.25-mm Endecott mesh. The samples were then stored in airtight Tedlar bags and preserved in a $-18{ }^{\circ} \mathrm{C}$ in freezer. Ethanol (Reagent grade VWR Chemicals, Belgium), acetone (Reagent grade VWR Chemicals, Belgium), methanol (Analytical grade, ProLabo, EEC), Folin-Ciocalteu's phenol reagent (analytical grade, Chemical Lab, Belgium), 2,2-diphenyl1picrylhydrazyl radical (DPPH) (Analytical grade, SigmaAldrich, St Louis, MO, USA), Gallic acid (Analytical grade, Sigma-Aldrich, St Louis, MO, USA) and sodium carbonate (Reagent grade Merck chemical, Darmstadt, Germany) were utilized as chemical inputs.

\section{Methods \\ Waste apple pomace (WAP) characterization}

Proximate analyses to determine the moisture content, fixed carbon content, volatile matter and ash contents of the WAP sample were undertaken according to the standard methods of the ASTM E1756-08 (ASTM 2015), ASTM method D3172-07 (ASTM 2007), ASTM D317511 (ASTM 2011), and ASTM D 2017-98 (ASTM 1998), respectively. The elemental analysis was undertaken using an elemental analyzer (LECO TruSpec CHN, Saint Joseph, Michigan, USA) to determine the carbon, hydrogen, nitrogen, and sulphur contents of the WAP sample. The elemental oxygen content was determined by subtracting the fractional ash, carbon, hydrogen, nitrogen, and sulphur contents from unity (Okoro et al. 2018). The lipid content was determined using the Soxhlet method (Kim et al. 2012). The protein content was determined according to the AOCS official method Ba4e-93 (AOAC 1998). The lignin content was determined using the Klason method (Carrier et al. 2011). The total carbohydrate content was determined by the difference (Okoro et al. 2018).

\section{Extraction procedures of polyphenolic compounds}

Solid-liquid extractions using three different solvents of water-only (designated as 100 WA henceforth), 50\% ethanol-50\% water v/v (designated as $50 \mathrm{ETH}$ henceforth), and $65 \%$ acetone-35\% water $\mathrm{v} / \mathrm{v}$ (designated as $65 \mathrm{ACE}$ henceforth) were carried out for the recovery of polyphenolic compounds present in dry AP sample. To this end, the extraction operating parameters were selected based on previous optimization studies for enhanced TPC extraction (Candrawinata et al. 2014; Ibrahim et al. 2019; Zardo et al. 2020). Optimal TPC extraction with 100 WA was attained at solid (dry apple pomace) massto-solvent volume ratio of $1: 20 \mathrm{~g} / \mathrm{mL}$ (Candrawinata et al. 2014). The optimal TPC extraction using ethanol has been achieved using $50 \mathrm{ETH}$ and a solid-to-solvent ratio of 1:80 g/mL (Zardo et al. 2020). When 65 ACE was employed, the solid-to-solvent ratio of $1: 100 \mathrm{~g} / \mathrm{mL}$ was imposed (Ibrahim et al. 2019). The experiments were undertaken in a $50 \mathrm{~mL}$ laboratory flask with continuous stirring at $200 \mathrm{rpm}$. For the kinetic studies, when 100 WA was used for extraction, the experiments were run at $85^{\circ} \mathrm{C}, 60^{\circ} \mathrm{C}$, and $40^{\circ} \mathrm{C}$. For extraction with $50 \mathrm{ETH}$ or 65 ACE, the experiments were carried out at $60{ }^{\circ} \mathrm{C}, 40{ }^{\circ} \mathrm{C}$, and $20{ }^{\circ} \mathrm{C}$. In all mentioned experimental conditions, extraction times were assessed at $5 \mathrm{~min}, 10 \mathrm{~min}, 15 \mathrm{~min}$, $20 \mathrm{~min}, 25 \mathrm{~min}, 30 \mathrm{~min}$, and $40 \mathrm{~min}$. After the extraction, the samples were centrifuged at $6000 \mathrm{~g}$ for $10 \mathrm{~min}$ for extraction with ethanol and acetone, and $9000 \mathrm{~g}$ for 10 min for water extraction. Finally, the supernatant was carefully collected for TPC determination.

\section{Determination of total polyphenolic content (TPC)}

The TPC of the extracts was determined using the FolinCiocalteu colorimetric method as described in the literature (Li et al. 2020). Briefly, $50 \mu \mathrm{L}$ of the extract was mixed with $250 \mu \mathrm{L}$ Folin-Ciocalteu reagent $(2 \mathrm{M})$ and $3 \mathrm{~mL}$ of distilled water and vortexed for $10 \mathrm{~s}$. Then, $1 \mathrm{~mL}$ of $15 \%$ (w/v) $\mathrm{Na}_{2} \mathrm{CO}_{3}$ solution was added, and subsequently, the volume of the mixture was brought up to $5 \mathrm{~mL}$ by adding $700 \mu \mathrm{L}$ of distilled water, vortexed for another $10 \mathrm{~s}$ and incubated at $20^{\circ} \mathrm{C}$ in dark for $1 \mathrm{~h}$. Finally, the absorbance of the resulting solution was measured using UV-visible spectrophotometer (PerkinElmer Lambda 25, MA, USA) at $765 \mathrm{~nm}$. The TPC was expressed as milligrammes of gallic acid equivalents (determined by a standard curve) per gramme of dry weight basis of AP (mg GAE/g db) as follows:

$$
\mathrm{TPC}=\frac{C \times V}{m},
$$

where $C$ denotes the sample concentration $(\mathrm{mg} / \mathrm{mL})$ obtained from the standard curve, $V$ is the volume of the solvent used for the extraction, and $m$ represents the weight $(\mathrm{g})$ of the dried AP sample used for the extraction.

\section{Kinetic modelling for the extraction methods}

In this study, first-order and second-order kinetic models were employed in modelling the extraction of bioactive polyphenolic compounds from AP by considering solid-liquid extractions using three different solvents of $100 \mathrm{WA}, 50 \mathrm{ETH}$, and $65 \mathrm{ACE}$. Briefly, the 
first-order extraction kinetic model as proposed by Harouna-Oumarou et al. (2007) has been assessed such that the rate of leaching $\left(r_{e}\right)$ is proportional to a driving force $\left(C_{s}-C_{t}\right)$ and the first-order rate equation is correlated with the idea of a linear driving force as shown in Eq. (2):

$$
r_{e}=\frac{\mathrm{d} C_{t}}{\mathrm{~d} t}=k\left(C_{s}-C_{t}\right),
$$

where $C_{t}(\mathrm{mg} \mathrm{GAE} / \mathrm{g} \mathrm{db})$ is the extraction capacity (concentration of TPC) at a given extraction time $t, C_{s}(\mathrm{mg}$ $\mathrm{GAE} / \mathrm{g} \mathrm{db}$ ) is the concentration of TPC at saturation point and $k$ is the first-order extraction rate coefficient $\left(\min ^{-1}\right)$.

A linear equation (Eq. 3) is obtained by the integration of Eq. (2) at the boundary conditions of $C_{t}=0$ at $t=0$ and $C_{t}=C_{t}$ at $t=t$, such that plotting $\ln$ values against $t$ provides the slope that can be used in the determination of first-order extraction rate constant:

$$
\ln \left[\frac{C_{s}}{C_{s}-C_{t}}\right]=k t \text {. }
$$

In such solid-liquid extractions, the Arrhenius-type equation was proposed to investigate the relation of extraction rate to temperature and so the temperature dependence of the extraction kinetics (Balyan and Sarkar 2016).

Therefore, further determination of the kinetic parameters was based on the Arrhenius-type equation as shown in Eqs. (4) and (5) (Shewale and Rathod 2018). The kinetic parameters $\left(A_{e}\right.$ and $\left.E_{a}\right)$ are calculated by plotting $\ln k$, against $1 / T$ (Eq. 4 ) and the slope and the intercept give the $E_{a}$ and the $A_{e}$, respectively:

$$
\begin{aligned}
& k=A_{e} e^{-\left[\frac{E_{a}}{R T}\right]}, \\
& \ln k=\ln A_{e}-\frac{E_{a}}{R T} .
\end{aligned}
$$

In Eqs. (4) and (5), $k, A_{e}, E_{a}, R$, and $T$ represent the approximate overall rate constant, in $\mathrm{min}^{-1}$; preexponential constant (Arrhenius constant), in $\mathrm{min}^{-1}$; activation energy, in $\mathrm{kJ} / \mathrm{kmol}$; universal gas constant, specified as $8.314 \mathrm{~kJ} / \mathrm{kmol} . \mathrm{K}$ and temperature in $\mathrm{K}$, respectively.

The second-order extraction kinetics is, however, modelled using Eq. (6) (Harouna-Oumarou et al. 2007):

$$
r_{e}=\frac{\mathrm{d} C_{t}}{\mathrm{~d} t}=k\left(C_{s}-C_{t}\right)^{2} .
$$

Such that the integration of Eq. (6), using the boundary conditions $C_{t}=0$ at $t=0$ and $C_{t}=C_{t}$ at $t=t$ is as follows:

$$
\frac{1}{C_{s}-C_{t}}-\frac{1}{C_{s}}=k t,
$$

or

$$
C_{t}=\frac{C_{s}^{2} k t}{1+C_{s} k t} .
$$

Equation (8) was then rearranged in a linearized form to give Eqs. (9) and (10) as follows:

$$
\begin{aligned}
& \frac{t}{C_{t}}=\frac{t}{C_{s}}+\frac{1}{C_{s}^{2} k}, \\
& \frac{t}{C_{t}}=\frac{t}{C_{s}}+\frac{1}{m},
\end{aligned}
$$

where $m$ denotes the initial extraction rate coefficient and is equal to $k C_{s}^{2}$.

The second-order extraction rate coefficient is calculated from the intercept obtained through plotting $t / C_{t}$ against $t$ using Eq. (10).

The values of the other kinetic parameters $\left(A_{e}, E_{a}\right)$ were determined using Eqs. (4) and (5), where $k$ and $A_{e}$ have units of $\mathrm{g} /(\mathrm{mg} \mathrm{min})$ for the second-order extraction process.

All experiments were conducted in triplicates and data were subsequently analysed.

\section{Determination of the antioxidant activity of apple pomace extracts based on DPPH inhibition activity}

The radical scavenging capacity of TPC extracts of AP against 2,2-diphenyl-1 picrylhydrazyl radical (DPPH) was conducted based on the method described in de Torre et al. (2019). The sample extracts of $100 \mathrm{WA}, 50 \mathrm{ETH}$, and 65 ACE containing the highest TPC concentration were selected as representative extracts for the DPPH determination experiments. $150 \mu \mathrm{L}$ of each extract was mixed with $150 \mu \mathrm{L}$ of DPPH solution in methanol $(0.04 \mathrm{mg} / \mathrm{mL})$ in a 96-well plate. After incubation in dark for $40 \mathrm{~min}$, the absorbance of the sample at $517 \mathrm{~nm}$ was recorded using a UV-Vis Spectrophotometer (Microplate spectrophotometer, Epoch-BioTek, Winooski, USA), and the percentage of DPPH inhibition activity of the sample extract was calculated as follows:

$$
\% \text { Inhibition }=1-\frac{\mathrm{Abs}_{s}-\mathrm{Abs}_{b}}{\mathrm{Abs}_{c}-\mathrm{Abs}_{b}} \times 100,
$$

where $\mathrm{Abs}_{s}$ denotes the absorbance of the sample (sample extract + DPPH solution), $\mathrm{Abs}_{b}$ denotes the absorbance of the sample blank (sample extract + methanol), and $A b s_{c}$ denotes the absorbance of the control (extraction solvent + DPPH solution). 
Table 1 Characterization results for waste apple pomace

\begin{tabular}{lc}
\hline WAP characterization & Measured value \\
\hline Moisture content (\% w/w, wet WAP basis) & $67.3 \pm 1.06$ \\
Lipid content (\% w/w, dry WAP basis) & $1.29 \pm 0.52$ \\
Carbohydrate content (\% w/w, dry WAP basis) & $71.9 \pm 1.30$ \\
Protein content (\% w/w, dry WAP basis) & $5.94 \pm 0.20$ \\
Lignin content (\% w/w, dry WAP basis) & $19.5 \pm 1.18$ \\
Ash content (\% w/w, dry WAP basis) & $1.30 \pm 0.00$ \\
Volatiles (\% w/w, dry WAP basis) & $92.4 \pm 0.00$ \\
Fixed carbon(\% w/w, dry WAP basis) & $6.34 \pm 0.00$ \\
Carbon content (\% w/w, dry WAP basis) & $46.1 \pm 0.64$ \\
Hydrogen content (\% w/w, dry WAP basis) & $6.87 \pm 0.11$ \\
Nitrogen content (\% w/w, dry WAP basis) & $0.95 \pm 0.03$ \\
Oxygen content (\% w/w, dry WAP basis) & $46.0 \pm 0.65$ \\
Sulphur content $(\% \mathrm{w} / \mathrm{w}$, dry WAP basis) & $0.07 \pm 0.01$ \\
\hline
\end{tabular}

\section{Results and discussion}

\section{Waste apple pomace characterization}

The physicochemical characterization of AP is displayed in Table 1. Based on the elemental analysis, the greatest elemental amount corresponds to carbon with a $46.1 \%$ $\mathrm{w} / \mathrm{w}$, followed by oxygen with $46.0 \% \mathrm{w} / \mathrm{w}$ and hydrogen with $6.87 \% \mathrm{w} / \mathrm{w}$. Nitrogen and sulphur with the values of 0.95 and $0.07 \% \mathrm{w} / \mathrm{w}$ constituted the lowest amounts in AP. Our results are in accordance with those found in previous studies with ranges obtained at $44.6-48.8 \% \mathrm{w} / \mathrm{w}$ for carbon, $37.4-45.7 \% \mathrm{w} / \mathrm{w}$ for oxygen, $6.18-6.65 \% \mathrm{w} / \mathrm{w}$ for hydrogen, $0.42-1.70 \% \mathrm{w} / \mathrm{w}$ for nitrogen (Gowman et al. 2019). The moisture content was detected as $67.3 \%$ which has been reported to range from $40-82.7 \%$ (Okoro and Shavandi, 2021). Moreover, there was low ash content $(1.30 \% \mathrm{w} / \mathrm{w})$ and high volatile content $(92.4 \%)$ which are within the range of $0.50-4.29 \%$ (Antonic et al. 2020) and comparable to $81.3 \%$ (Guerrero et al. 2014) for ash and volatile contents, of typical lignocellulosic biomass. The mean contents of carbohydrate, protein, and lipid were determined at $71.9 \% \mathrm{w} / \mathrm{w}, 5.94 \% \mathrm{w} / \mathrm{w}$, and $1.29 \%$ $\mathrm{w} / \mathrm{w}$, respectively, and was within the ranges of $48-84 \%$ $\mathrm{w} / \mathrm{w}$ for carbohydrate (Bhushan et al. 2008; Lyu et al. $2020 \mathrm{~b}), 1.2-6.91 \% \mathrm{w} / \mathrm{w}$ for protein and $0.26-8.49 \% \mathrm{w} / \mathrm{w}$ for lipid contents (Antonic et al. 2020) reported in the literature. The lignin content of $19.5 \% \mathrm{w} / \mathrm{w}$ was also within the range expected in AP 15.3-23.5\% w/w (Vidović et al. 2020).

\section{Kinetics of water-only extraction of total polyphenolic compounds from waste apple pomace}

Experimental results for the extraction kinetics of the TPC from AP at different temperatures $\left(40^{\circ} \mathrm{C}, 60^{\circ} \mathrm{C}\right.$, and $85^{\circ} \mathrm{C}$ ) with water-only are depicted in Table 2 . A rapid
Table 2 Total polyphenolic compound (TPC) extraction from apple pomace (AP) with water-only at solid/solvent ratio 1:20 g/ $\mathrm{mL}$, under continuous magnetic stirring at $200 \mathrm{rpm}$

\begin{tabular}{|c|c|c|}
\hline Temperature $\left({ }^{\circ} \mathrm{C}\right)$ & Time (min) & TPC (mg GAE/g db) \\
\hline \multirow[t]{7}{*}{85} & 0 & 0 \\
\hline & 5 & $3.02 \pm 0.12$ \\
\hline & 10 & $4.14 \pm 0.02$ \\
\hline & 15 & $4.27 \pm 0.11$ \\
\hline & 25 & $4.36 \pm 0.18$ \\
\hline & 30 & $4.45 \pm 0.18$ \\
\hline & 40 & $3.51 \pm 0.14$ \\
\hline \multirow[t]{7}{*}{60} & 0 & 0 \\
\hline & 5 & $4.15 \pm 0.15$ \\
\hline & 10 & $4.29 \pm 0.13$ \\
\hline & 15 & $4.36 \pm 0.09$ \\
\hline & 25 & $4.93 \pm 0.14$ \\
\hline & 30 & $5.09 \pm 0.06$ \\
\hline & 40 & $3.33 \pm 0.30$ \\
\hline \multirow[t]{6}{*}{40} & 0 & 0 \\
\hline & 5 & $2.28 \pm 0.04$ \\
\hline & 10 & $2.67 \pm 0.12$ \\
\hline & 15 & $3.07 \pm 0.06$ \\
\hline & 25 & $3.66 \pm 0.08$ \\
\hline & 30 & $3.33 \pm 0.08$ \\
\hline
\end{tabular}

increase in extracted TPC was observed at the beginning of the process ( $\sim$ within $5 \mathrm{~min})$. Then the gradual and slow increase trend was distinguished in the further progress of the extraction process and continued till the peak point was reached where a maximum of TPC was extracted. This observation can be explained based on Fick's law. According to Fick's law, at the beginning of an extraction process, high concentration gradient between the solid phase (AP) and liquid phase (solvent) results in high diffusion of polyphenolic compounds into the solvent. As the extraction continues, the concentration gradient gets smaller; thereby increasing the extraction yield until the peak point is attained (Harouna-Oumarou et al. 2007). Notably, Table 2 also shows that the extracted TPC was reduced beyond the peak point in all conditions. This observation may be attributed to the oxidation and decomposition of TPC leading to thermal degradation of polyphenolic compounds with sustained heating and long extraction time (Narayana Namasivayam et al. 2018; Perussello et al. 2017). This statement is consistent with literature since polyphenol stability, is recognized as a challenge for the food industry and is sensitive to temperature, $\mathrm{pH}$ and even light exposure (Diaconeasa 2018). Therefore, in assessing the kinetics of TPC extraction, the values beyond the peak values have not been considered in the modelling. Indeed, they do not reflect 
the extraction kinetics of TPC but are rather a representation of the thermal degradation rates of the extracted TPC. Table 2 also shows that the highest TPC value at $60{ }^{\circ} \mathrm{C}$ is $5.10 \pm 0.06 \mathrm{mg} \mathrm{GAE} / \mathrm{g} \mathrm{db}$ in $30 \mathrm{~min}$, while at temperatures of $85^{\circ} \mathrm{C}$ and $40{ }^{\circ} \mathrm{C}$, the highest TPC values of $4.45 \pm 0.18 \mathrm{mg} \mathrm{GAE} / \mathrm{g} \mathrm{db}$ and $3.67 \pm 0.08 \mathrm{mg} \mathrm{GAE} / \mathrm{g}$ $\mathrm{db}$ were achieved, respectively. The results indicate that the influence of changes in temperature constitutes an important extraction parameter that influences the recovery of TPC, as expected. The influence of increasing temperature on the extraction efficiency of TPC could be due to the increased solubility of polyphenolic compounds in the solvent and their enhanced diffusion rate and mass transfer from the solid matrix to the solvent (Shewale and Rathod, 2018). However, the maximum TPC yield of $4.45 \pm 0.18 \mathrm{mg} \mathrm{GAE} / \mathrm{g} \mathrm{db}$ obtained at $85^{\circ} \mathrm{C}$ was lower than the TPC value of $5.09 \pm 0.06 \mathrm{mg} \mathrm{GAE} / \mathrm{g}$ $\mathrm{db}$ at $60^{\circ} \mathrm{C}$. This could be due to the thermal degradation of heat-sensitive polyphenolic compounds (Perussello et al. 2017), discussed above.

\section{First-order kinetic model for water-only extraction of TPC from waste apple pomace}

For the first-order kinetic model, the experimental data of the extraction kinetics (Table 2) were plotted as $\ln \left(C_{s} /\right.$ $\left(C_{s}-C_{t}\right)$ ) versus $t$. The resulting plot was used to determine the values of first-order rate constant $(k)$ and coefficient of determination $\left(R^{2}\right)$ (Fig. 1a-c). The plot shows that the extraction of TPC of AP can be represented by a linear form of the first-order model. The $k$ value increased with increasing temperature and obtained values are
$0.129 \mathrm{~min}^{-1}, 0.145 \mathrm{~min}^{-1}$, and $0.182 \mathrm{~min}^{-1}$ at reaction temperatures of $40{ }^{\circ} \mathrm{C}, 60{ }^{\circ} \mathrm{C}$, and $85{ }^{\circ} \mathrm{C}$, respectively. This observation shows that a positive correlation exists between the extraction rate and the temperature, thus reinforcing the importance of the elevated temperatures on the extraction rate of TPC with 100 WA solvent. The mean $R^{2}$ value of the extraction kinetics models obtained for the different temperatures (Fig. 1a-c) was shown to be 0.864 (i.e. from $0.803,0.856$ and 0.932 ).

\section{Second-order kinetic model for water-only extraction of TPC from waste apple pomace}

The second-order kinetic model was also assessed to determine its sufficiency in describing the kinetics of TPC extraction from AP. Following Eqs. 9 and 10, plots of $t / C_{t}$ versus $t$ were generated and the values of the secondorder rate constant $(k)$ and coefficient of determination $\left(R^{2}\right)$, subsequently determined (Figs. $1 \mathrm{~d}-\mathrm{f}$ ). The values of the $k$ were determined at $0.123 \mathrm{~g} /(\mathrm{mg} \mathrm{min}), 0.163 \mathrm{~g} /(\mathrm{mg}$ min), and $0.224 \mathrm{~g} /(\mathrm{mg} \mathrm{min})$ at $40{ }^{\circ} \mathrm{C}, 60{ }^{\circ} \mathrm{C}$, and $85{ }^{\circ} \mathrm{C}$, respectively, showing its increasing trend with a temperature rise. As shown in Fig. 1d-f, comparatively higher $R^{2}$ values (an average value of 0.983 ) were observed for the second-order kinetic model in comparison to the firstorder kinetic fit. This observation shows that the secondorder kinetics is a more suitable model for describing the kinetic extraction process of TPC with water-only, which can be concluded that more than one mechanism contributes to the extraction process (Harouna-Oumarou et al. 2007).

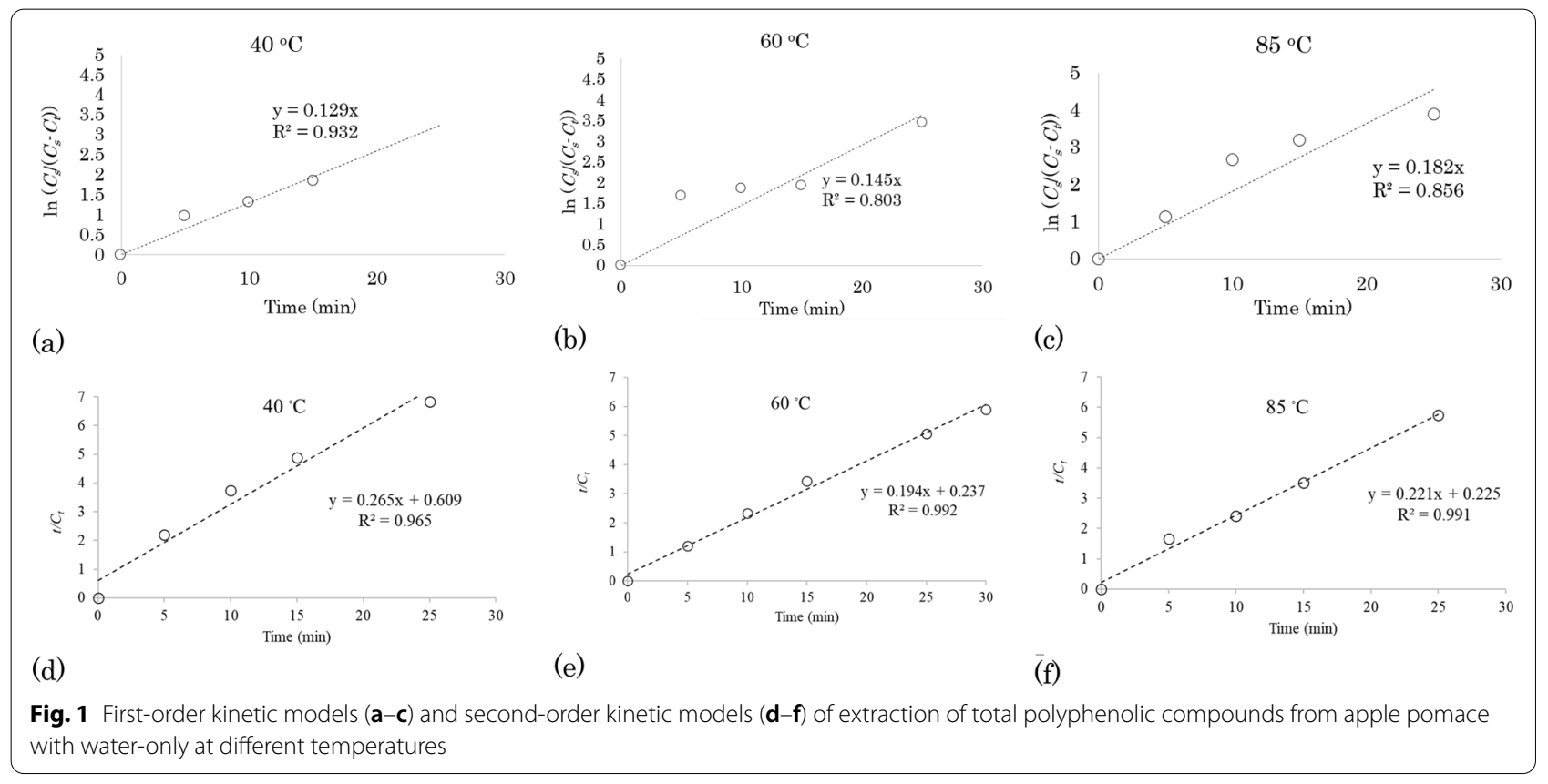


Kinetics of ethanol-water extraction of total polyphenolic compounds from waste apple pomace

Experimental results for the extraction of TPC from AP at different temperatures $\left(20^{\circ} \mathrm{C}, 40{ }^{\circ} \mathrm{C}\right.$, and $60{ }^{\circ} \mathrm{C}$ ) using $50 \mathrm{ETH}$ are depicted in Table 3. Similar to TPC extraction with water-only, a rapid increase of TPC extraction was observed during the initial 5 min which

Table 3 Total polyphenolic compound (TPC) from apple pomace with $50 \mathrm{ETH}$ at solid/solvent ratio of $1: 80 \mathrm{~g} / \mathrm{mL}$, under continuous magnetic stirring at $200 \mathrm{rpm}$

\begin{tabular}{|c|c|c|}
\hline Temperature $\left({ }^{\circ} \mathrm{C}\right)$ & Time (min) & $\mathrm{TPC}(\mathrm{mg} \mathrm{GAE} / \mathrm{g} \mathrm{db})$ \\
\hline \multirow[t]{6}{*}{60} & 0 & 0 \\
\hline & 5 & $8.54 \pm 0.20$ \\
\hline & 10 & $8.72 \pm 0.41$ \\
\hline & 15 & $8.85 \pm 0.12$ \\
\hline & 20 & $9.19 \pm 0.36$ \\
\hline & 25 & $9.06 \pm 0.44$ \\
\hline \multirow[t]{6}{*}{40} & 0 & 0 \\
\hline & 5 & $7.24 \pm 0.34$ \\
\hline & 10 & $7.58 \pm 0.12$ \\
\hline & 15 & $7.68 \pm 0.12$ \\
\hline & 20 & $8.05 \pm 0.32$ \\
\hline & 25 & $7.76 \pm 0.35$ \\
\hline \multirow[t]{6}{*}{20} & 0 & 0 \\
\hline & 5 & $6.02 \pm 0.45$ \\
\hline & 10 & $6.38 \pm 0.27$ \\
\hline & 15 & $6.46 \pm 0.36$ \\
\hline & 20 & $7.06 \pm 0.47$ \\
\hline & 25 & $6.77 \pm 0.21$ \\
\hline
\end{tabular}

can be attributed to the rapid diffusion of ethanolwater-soluble TPC into the solvent solution (Cavdarova and Makris 2014). The highest TPC of $9.19 \pm 0.36 \mathrm{mg}$ $\mathrm{GAE} / \mathrm{g} \mathrm{db}$ was achieved at $60{ }^{\circ} \mathrm{C}$ in 20 min of extraction compared to TPCs of $8.05 \pm 0.32$ and $7.06 \pm 0.47 \mathrm{mg}$ $\mathrm{GAE} / \mathrm{g} \mathrm{db}$ at $40{ }^{\circ} \mathrm{C}$ and $20{ }^{\circ} \mathrm{C}$, respectively, thus highlighting the favourable role of (increasing) temperature on TPC extraction. The synergistic effect of the water and alcohol on the TPC extraction efficiency may explain the high TPC achieved. This is because the water and ethanol mixture may increase the contact surface of AP particles and ethanol by weakening the bonds between polyphenolics-protein and polyphenolics-cellulose, thus enhancing the extraction efficiency (Rodriguez De Luna et al. 2020).

\section{First-order kinetic model for ethanol-water extraction of TPC} from waste apple pomace

The experimental data of the extraction kinetics (Table 3) were processed and by plotting $\ln \left(C_{s} /\left(C_{s}-C_{t}\right)\right)$ versus $t$, the values of rate constant $(k)$ and coefficient of determination $\left(\mathrm{R}^{2}\right)$ were obtained (Fig. $2 \mathrm{a}-\mathrm{c}$ ). The $k$ values $0.200 \mathrm{~min}^{-1}, 0.247 \mathrm{~min}^{-1}$, and $0.265 \mathrm{~min}^{-1}$ were obtained at reaction temperatures of $20{ }^{\circ} \mathrm{C}, 40{ }^{\circ} \mathrm{C}$, and $60{ }^{\circ} \mathrm{C}$, respectively, which shows that raising the temperature could enhance the rate of extraction of TPC. However, relatively low $R^{2}$ values ranging from 0.663 to 0.725 (mean 0.691 ) were achieved which can be concluded that the first-order kinetic model cannot well describe the extraction of TPC of AP with $50 \mathrm{ETH}$.

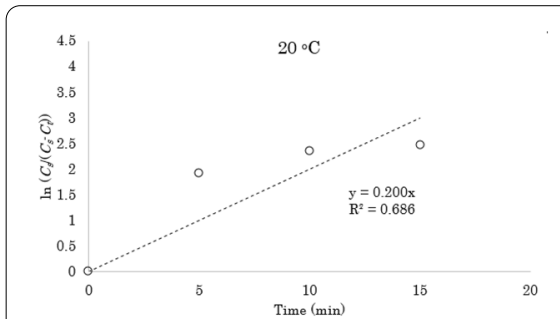

(a)

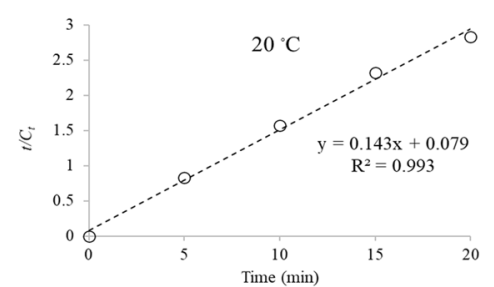

(d)

Fig. 2 First-order kinetic models $(\mathbf{a}-\mathbf{c})$ and second-order kinetic models $(\mathbf{d}-\mathbf{f})$ of extraction of total polyphenolic compounds from waste apple pomace using 50\% ethanol-50\% water $\mathrm{v} / \mathrm{v}$ at different temperatures

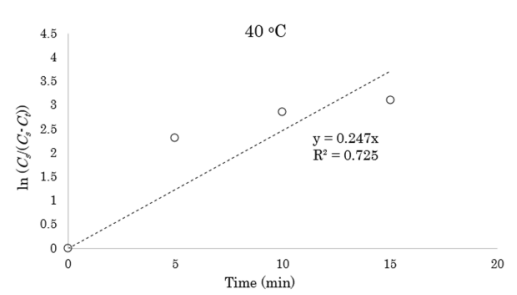

(b)

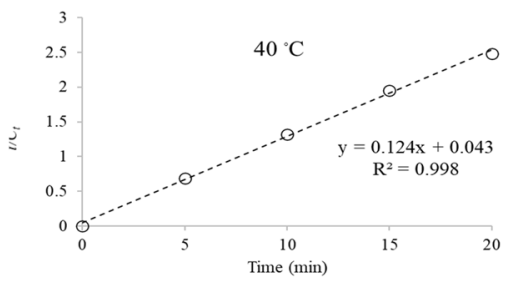

(e)

(c)

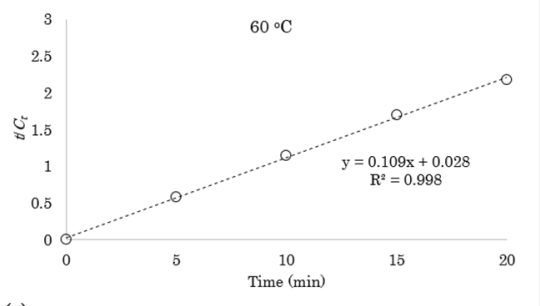

(f)

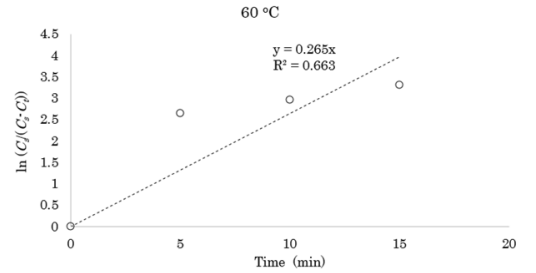




\section{Second-order kinetic model for ethanol-water extraction of TPC from waste apple pomace}

The second-order kinetic model was employed to investigate the release kinetics of TPC extraction from AP by determination of the values of rate constant $(k)$ and coefficient of determination $\left(R^{2}\right)$ (Fig. $2 \mathrm{~d}-\mathrm{f}$ ). The best fits were acquired when the second-order kinetic model was applied compared with the first-order kinetic model and $k$ values were determined to be $0.254 \mathrm{~g} /(\mathrm{mg} \mathrm{min}), 0.359 \mathrm{~g} /$ (mg min) and $0.419 \mathrm{~g} /(\mathrm{mg} \mathrm{min})$ at reaction temperatures of $20{ }^{\circ} \mathrm{C}, 40{ }^{\circ} \mathrm{C}$ and $60{ }^{\circ} \mathrm{C}$. Figure $2 \mathrm{~d}-\mathrm{f}$ also shows higher $R^{2}$ values ranging from 0.993 to 0.998 (i.e. mean 0.996 ), which indicates that the second-order kinetic model can be used to study the extraction of TPC from AP with 50 $\mathrm{ETH}$ in which temperature has a significant influence on extraction rate.

\section{Kinetics of acetone-water extraction of total polyphenolic compounds from waste apple pomace}

Experimental results for the extraction kinetics of TPC from AP at different temperatures $\left(20{ }^{\circ} \mathrm{C}, 40{ }^{\circ} \mathrm{C}\right.$, and $60{ }^{\circ} \mathrm{C}$ ) in $65 \mathrm{ACE}$ are shown in Table 4 . Table 4 also shows a rapid increase in the concentration of TPC extraction during the initial $5 \mathrm{~min}$ of the reaction followed by a gradual rise. The highest yield of TPC $(11.1 \pm 0.49 \mathrm{mg}$ $\mathrm{GAE} / \mathrm{g} \mathrm{db}$ ) was achieved at the temperature of $60^{\circ} \mathrm{C}$ after $30 \mathrm{~min}$ of the extraction. At the temperatures of $40{ }^{\circ} \mathrm{C}$ and $20{ }^{\circ} \mathrm{C}$, TPC values of $9.37 \pm 0.46$ and $8.98 \pm 0.71 \mathrm{mg}$ $\mathrm{GAE} / \mathrm{g} \mathrm{db}$ were measured, respectively. These observations highlight the influence of temperature on the extraction process. The high efficiency of acetone-water solvent for TPC extraction from AP is attributed to its potential for facilitating the extraction of non-polar and polar TPCs (Mokrani and Madani 2016).

\section{First-order kinetic model for acetone-water extraction of TPC from waste apple pomace}

First-order kinetic models were achieved based on the experimental data of the extraction kinetics (Table 4). The first-order rate constant $(k)$ and coefficient of determination $\left(R^{2}\right)$ were obtained by plotting $\ln \left(C_{s} /\left(C_{s}-C_{t}\right)\right)$ versus $t$ (Fig. 3a-c). The extraction of 65 ACE soluble TPC of AP can be represented in the linear form according to the first-order model. The $k$ values decreased from $0.163 \mathrm{~min}^{-1}$ to $0.154 \mathrm{~min}^{-1}$, when the temperature was increased from 20 to $40{ }^{\circ} \mathrm{C}$ (Fig. $3 \mathrm{~d}-\mathrm{f}$ ); however, at $60{ }^{\circ} \mathrm{C}$, the $k$ value $\left(0.156 \mathrm{~min}^{-1}\right)$ was comparable to $k$ value at $40{ }^{\circ} \mathrm{C}\left(0.154 \mathrm{~min}^{-1}\right)$. This observation may indicate that there is no positive correlation between the $k$ values and the temperatures. Therefore, it can be concluded the rate of TPC extraction from AP using $65 \mathrm{ACE}$ is higher $\left(0.163 \mathrm{~min}^{-1}\right)$ at low temperatures (i.e. $20{ }^{\circ} \mathrm{C}$ )
Table 4 Total polyphenolic compound (TPC) from apple pomace with $65 \%$ aqueous acetone-35\% water $\mathrm{v} / \mathrm{v}$ at solid/ solvent ratio of $1: 100 \mathrm{~g} / \mathrm{mL}$, under continuous magnetic stirring at $200 \mathrm{rpm}$

\begin{tabular}{|c|c|c|}
\hline Temperature $\left({ }^{\circ} \mathrm{C}\right)$ & Time (min) & TPC (mg GAE/g db) \\
\hline \multirow[t]{7}{*}{60} & 0 & 0 \\
\hline & 5 & $8.85 \pm 0.35$ \\
\hline & 10 & $9.05 \pm 0.26$ \\
\hline & 15 & $9.57 \pm 0.44$ \\
\hline & 20 & $10.6 \pm 0.43$ \\
\hline & 30 & $11.1 \pm 0.49$ \\
\hline & 40 & $10.3 \pm 0.50$ \\
\hline \multirow[t]{7}{*}{40} & 0 & 0 \\
\hline & 5 & $7.59 \pm 0.35$ \\
\hline & 10 & $8.11 \pm 0.37$ \\
\hline & 15 & $8.37 \pm 0.35$ \\
\hline & 20 & $8.76 \pm 0.20$ \\
\hline & 30 & $9.37 \pm 0.46$ \\
\hline & 40 & $8.63 \pm 0.20$ \\
\hline \multirow[t]{7}{*}{20} & 0 & 0 \\
\hline & 5 & $7.49 \pm 0.29$ \\
\hline & 10 & $8.07 \pm 0.64$ \\
\hline & 15 & $8.27 \pm 0.10$ \\
\hline & 20 & $8.33 \pm 0.46$ \\
\hline & 30 & $8.98 \pm 0.71$ \\
\hline & 40 & $8.76 \pm 0.35$ \\
\hline
\end{tabular}

than the rate of TPC extraction at higher temperatures $\left(0.154 \mathrm{~min}^{-1}\right.$ at $\left.40{ }^{\circ} \mathrm{C}\right)$. The efficiency of acetone extraction at low temperatures has been reported in the literature (Zardo et al. 2020). For instance in the research by Mokrani and Madani (2016), extraction of TPC from peach (Prunus persica L.) fruit with $60 \%$ acetone at $25{ }^{\circ} \mathrm{C}$ for $180 \mathrm{~min}$ gave the highest TPC of $363 \mathrm{GAE} / 100 \mathrm{~g}$ compared to applying temperatures of higher than $25^{\circ} \mathrm{C}$. We assert that the low temperature sufficiency of acetone to extract high concentrations of polyphenols is due to the ability of acetone to extract polar and non-polar polyphenols since it is comparatively less polar than ethanol and water, with higher temperatures potentially leading to a degradation of polyphenols extracted.

\section{Second-order kinetic model for acetone-water extraction of TPC from waste apple pomace}

The second-order kinetic models were employed to investigate the release kinetics of TPC from AP by determination of the values of rate constant $(k)$ and coefficient of determination $\left(R^{2}\right)$ (Fig. $3 \mathrm{~d}-\mathrm{f}$ ). The best fits were acquired when the second-order kinetic model was applied compared with the first-order kinetic model and $k$ values were determined $0.158 \mathrm{~g} /(\mathrm{mg} \mathrm{min}), 0.109 \mathrm{~g} /(\mathrm{mg}$ 


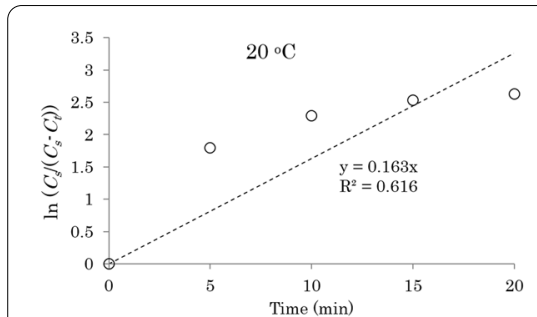

(a)

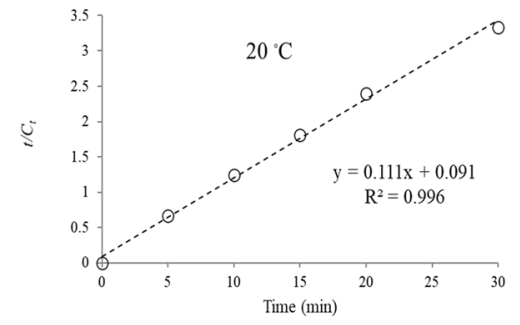

(d) with $65 \%$ acetone-35\% water $v / v$ at different temperatures

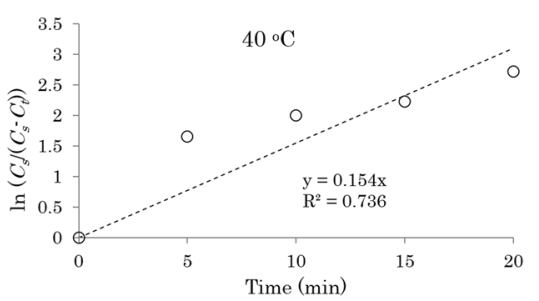

(b)

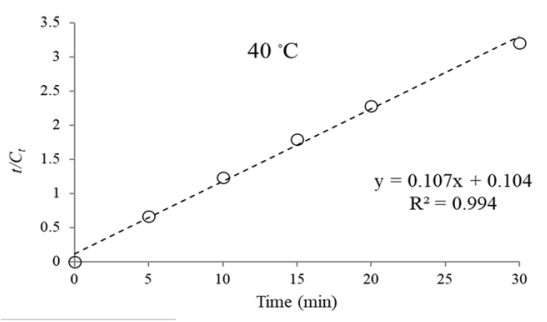

(e)

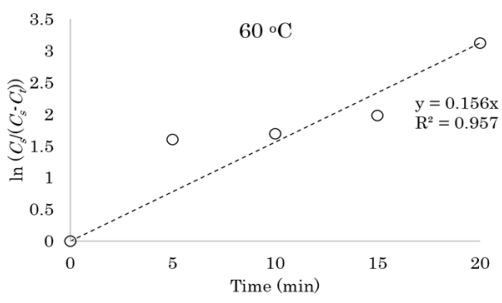

(c)

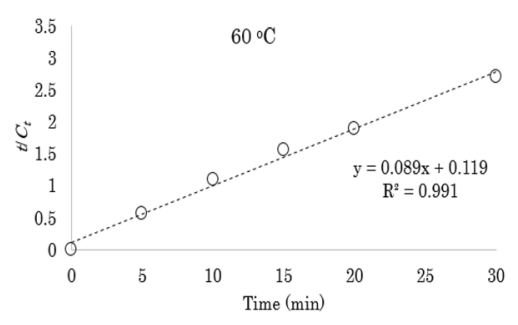

(f) $\mathrm{min})$, and $0.068 \mathrm{~g} /(\mathrm{mg} \mathrm{min})$ at reaction temperatures of $20{ }^{\circ} \mathrm{C}, 40{ }^{\circ} \mathrm{C}$, and $60{ }^{\circ} \mathrm{C}$ with higher $R^{2}$ values $(>0.99)$, indicating that the second-order kinetic model can be used to study the extraction of TPC from AP with 65 ACE. However, unlike the extraction with $100 \mathrm{WA}$ and $50 \mathrm{ETH}, k$ values exhibited a declining trend in response to an increasing temperature which could be confirmed the high efficiency of acetone in the extraction of TPC at low temperatures. Following our result, a study by (Makris and Kefalas 2015), demonstrated that $k$ values of the second-order kinetic model of polyphenol extraction from onion (Allium cepa) solid waste using the acidified water-ethanol mixture, decreased with increasing temperature from 20 to $40{ }^{\circ} \mathrm{C}$.

\section{Kinetic parameter determination}

The associated kinetic parameters were determined using the Arrhenius-type equation as discussed in "Kinetic modelling for the extraction methods" section above are discussed in the subsequent subsections.

\section{Water-only extraction of TPC from waste apple pomace}

To obtain the kinetic parameters, for the first-order kinetic model case, $\ln k$ was plotted against $1 / T$ (Fig. 4a1), the $E_{a}$ value for the extraction process was determined to be $7.14 \mathrm{~kJ} / \mathrm{mol}$ based on the fitted line characterized by the $R^{2}$ value of $\sim 0.974$. The pre-exponential factor, $A_{e}$, was also determined to be $1.92 \mathrm{~min}^{-1}$. The value of $E_{a}$ in extraction processes depends on different factors, such as the type of solvent, the target compounds, material matrix, and the pre-treatment of the sample
(Gonzalez-Centeno et al. 2015). Notably, the classification proposed for the $E_{a}$ values could be employed in identifying the mechanism that controls the extraction process. Thus, if $E_{a}>40 \mathrm{~kJ} / \mathrm{mol}$, the extraction is managed by solubilization mechanism, if $E_{a}<20$ the extraction is controlled by diffusion mechanism, and if $20<E_{a}$ $<40$, the extraction process is governed by a combination of diffusion and solubilization mechanisms (GonzalezCenteno et al. 2015). So, considering that the value of $E_{a}$ is $7.14 \mathrm{~kJ} / \mathrm{mol}$, we concluded that the extraction of TPC from AP with water is controlled by a diffusion mechanism. Similarly for the second-order case, using the Arrhenius equation the plot of Fig. 4(a2) was generated. In Fig. 4(a2), the $E_{a}$ value and pre-exponential factor $\left(A_{e}\right)$ were determined to be $12.4 \mathrm{~kJ} / \mathrm{mol}$ and $14.5 \mathrm{~g} /(\mathrm{mg} \mathrm{min})$, respectively, with an $R^{2}$ value of $\sim 0.999$. Notably, the $E_{a}$ value of $12.4 \mathrm{~kJ} / \mathrm{mol}$ also suggests that the extraction of TPC from AP using water-only is controlled by a diffusion mechanism.

\section{Ethanol-water extraction of TPC from waste apple pomace}

Using the Arrhenius equation, Fig. 4(b1 and b2) was generated. In Fig. 4(b1), the $E_{a}$ value and pre-exponential factor for the extraction process were determined to be $5.72 \mathrm{~kJ} / \mathrm{mol}$ and $2.13 \mathrm{~min}^{-1}$, respectively, based on the fitted line characterized by the $R^{2}$ value of $\sim 0.946$. In Fig. 4(b2), the $E_{a}$ value and pre-exponential factor for the extraction process were determined to be $10.2 \mathrm{~kJ} / \mathrm{mol}$ (i.e. a diffusion mechanism) and $17.5 \mathrm{~g} /(\mathrm{mg} \mathrm{min})$, respectively, with the 'line of best fit' having an $R^{2}$ of $\sim 0.968$, which is indicative of high levels of data correlation. 


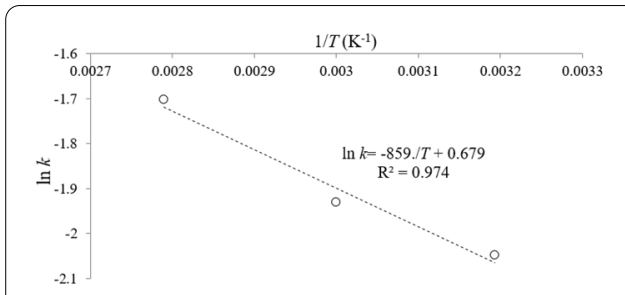

(a1)

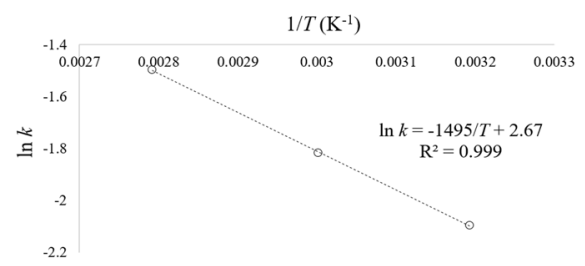

(a2)

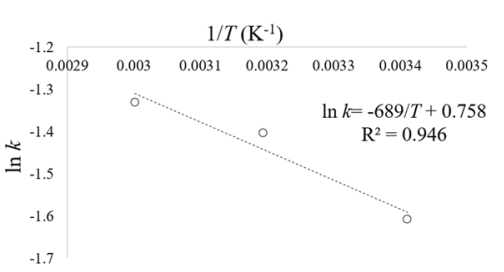

(b1)

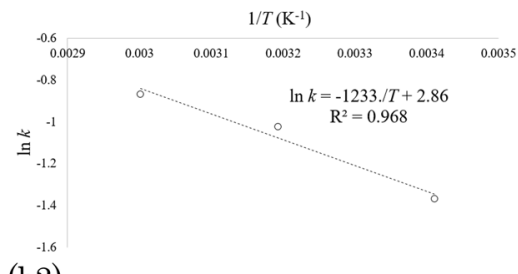

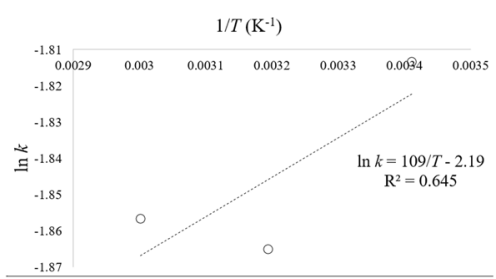

(c1)

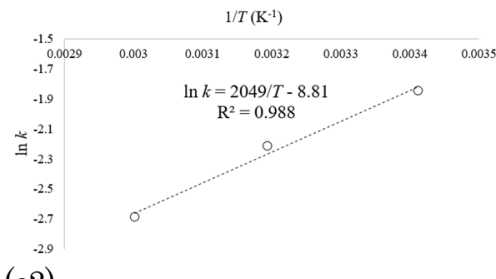

(c2)

Fig. 4 Arrhenius plot obtained from first-order kinetic parameters (a1) and from second-order kinetic model parameters (a2) for the extraction of total polyphenolic compounds from apple pomace with water-only. Arrhenius plot obtained from first-order kinetic parameters (b1) and from second-order kinetic model parameters (b2) for the extraction of total polyphenolic compounds from apple pomace with 50\% ethanol-50\% water $\mathrm{v} / \mathrm{V}$. Arrhenius plot obtained from first-order kinetic parameters (c1) and from second-order kinetic model parameters (c2 $)$ for the extraction of total polyphenolic compounds from apple pomace with 65\% acetone-35\% water v/v

Regarding the results of the activation energy obtained from the second-order kinetics of $100 \mathrm{WA}$ and $50 \mathrm{ETH}$ extraction, it can be concluded that the extraction of TPC with $50 \mathrm{ETH}$ requires a lower amount of energy which makes this mixture more efficient than water in TPC extraction of AP.

\section{Acetone-water extraction of TPC from waste apple pomace}

Using the Arrhenius equation and plotting $\ln k$ obtained from the first-order kinetic models against $1 / T$ (Fig. 4c1), considering the low value of $R^{2}(0.645)$ and the ascending trend of the fitted line which showed the opposite trend obtained for $100 \mathrm{WA}$ and $50 \mathrm{ETH}$ extractions. The low $R^{2}$ value of 0.645 suggests that the kinetic parameters of the extraction using $65 \mathrm{ACE}$ cannot be determined using the
Arrhenius equation since the lower temperatures tend to favour TPC extraction (i.e. higher $k$ values) as discussed above. For the second-order case (Fig. 4(c2)), the Arrhenius equation was employed to determine the activation energy and pre-exponential factor of the extraction process based on the data obtained for second-order kinetic models. Considering the Arrhenius plot, the high value of $R^{2}(0.988)$ was achieved; however, the opposite trend of the fitted line was observed and $E_{a}$ and $A_{e}$ values were achieved $-17.0 \mathrm{~kJ} / \mathrm{mol}$ and $0.00 \mathrm{~g} /(\mathrm{mg} \mathrm{min})$, respectively, indicating that the extraction with $65 \mathrm{ACE}$ does not obey the Arrhenius equation. This reinforces the assertion that increasing temperatures does not translate to higher TPC when the solvent of $65 \mathrm{ACE}$ is used.

Table 5 Kinetic parameters obtained from second-order model

\begin{tabular}{|c|c|c|c|c|c|c|c|}
\hline Solvent & $T\left({ }^{\circ} \mathrm{C}\right)$ & $\begin{array}{l}\text { Cs (mg GAE/g } \\
\mathrm{db})\end{array}$ & $k(g /(m g ~ \min ))$ & $R^{2}$ & $E_{a}(\mathrm{~kJ} / \mathrm{mol})$ & $A_{e}(\mathrm{~g} /(\mathrm{mg} \min ))$ & $R^{2}$ \\
\hline \multirow[t]{3}{*}{100 WA } & 40 & 3.77 & 0.123 & 0.965 & 12.4 & 14.5 & 0.999 \\
\hline & 60 & 5.15 & 0.163 & 0.992 & & & \\
\hline & 85 & 4.58 & 0.224 & 0.991 & & & \\
\hline \multirow[t]{3}{*}{$50 \mathrm{ETH}$} & 20 & 6.99 & 0.254 & 0.993 & 10.2 & 17.5 & 0.968 \\
\hline & 40 & 8.06 & 0.359 & 0.998 & & & \\
\hline & 60 & 9.16 & 0.419 & 0.998 & & & \\
\hline \multirow[t]{3}{*}{$65 \mathrm{ACE}$} & 20 & 9.01 & 0.158 & 0.996 & - & - & 0.988 \\
\hline & 40 & 9.34 & 0.109 & 0.994 & & & \\
\hline & 60 & 11.2 & 0.068 & 0.990 & & & \\
\hline
\end{tabular}




\section{Overview of the kinetic parameters of the second-order model}

Regarding the obtained kinetic data, the second-order kinetic model could adequately describe the extraction of TPC from AP for all the solvents as illustrated by the high coefficient of determination $\left(R^{2}>0.96\right)$ values in Table 5. The results showed that temperature is an important factor that influences TPC extraction from AP and has a significant effect on kinetic parameters. Regarding the results of $k$ values, higher $k$ values were obtained as the extraction temperature increased when $100 \mathrm{WA}$ and $50 \mathrm{ETH}$ solvents were used; however, this trend was not observed when extractions were undertaken using 65 ACE. This result indicates that better extraction efficiency with higher $k$ values can be achieved in lower temperatures $\left(<20^{\circ} \mathrm{C}\right)$ with 65 ACE. Table 5 also shows that the Arrhenius kinetic parameter of $E_{a}$ ranges from $10.2 \mathrm{~kJ} / \mathrm{mol}$ to $12.4 \mathrm{~kJ} / \mathrm{mol}$ for $50 \mathrm{ETH}$ and $100 \mathrm{WA}$, respectively, confirming the contribution of diffusion mechanism for the extraction of TPC from AP with these solvents. Notably, the values of $E_{a}$ and $A_{e}$ were obtained as $-17.0 \mathrm{~kJ} / \mathrm{mol}$ and $0.00 \mathrm{~g} /$ (mg min), respectively, in extraction with 65 ACE. This observation indicates that the Arrhenius equation cannot be applied to determine the kinetic parameters in extraction with 65 ACE because the Arrhenius-based correlation between temperatures and $k$ values was not observed. Therefore, the kinetic parameters describing total polyphenolic compound extraction from AP using 65 ACE were not reported in Table 5. For completeness, the statistical significance of the effects of the process parameters of temperature and time on TPC extractions were also assessed via ANOVA investigations in Minitab V17.1.0 (Matlab Inc. USA). The data is presented in the Additional file 1 . The parameters were determined to present statistically significant effects on TPC extractions for all solvents.

\section{Determination of the antioxidant activity of waste apple pomace extracts based on DPPH}

The DPPH inhibition of the polyphenolic compounds extracted using $100 \%$ water, $50 \%$ ethanol-water, and $65 \%$ acetone-water was determined. The extracts with the highest amount of TPC based on the kinetic results were then assessed. The extract of 65 ACE presented the highest antioxidant activity which can be explained by the higher amounts of TPC obtained with this solvent. The percentage of the DPPH radical scavenging activity was in the order of acetone-water $>$ ethanolwater $>$ water extraction with values of $95.2 \pm 3.34$, $92.5 \pm 1.36$, and $71.0 \pm 4.66 \%$, respectively. This study also confirms that the antioxidant activity of the extracts correlated with their TPC content. In a study by Suárez et al. (2010), acetonic (70\%) and methanolic $(80 \%)$ extracts of AP exhibited considerable antioxidant properties. In addition, a 1.4 times more DPPH radical scavenging activity was observed in acetonic extract compared to the methanolic extract (Bai et al. 2013). Furthermore, polyphenols isolated from AP showed 2-3 times higher DPPH radical scavenging activity than that of an equal concentration of vitamins $\mathrm{C}$ or $\mathrm{E}$ (Lu and Foo 2000). The results, therefore, reinforce the potential of AP as a cheap and readily available antioxidant source.

\section{Conclusion}

The kinetics of solid-liquid extraction of polyphenolic compounds from AP showed that the solvent type and the temperature have influence on TPC extraction efficiency. 65 ACE showed high efficiency in recovery of TPC. Furthermore, the study showed that high temperatures were not necessary for enhanced TPC extraction when the $65 \mathrm{ACE}$ was used compared to when the solvents of $100 \mathrm{WA}$ and $50 \mathrm{ETH}$ were used. As expected, the DPPH of the TPC via the 65 ACE solvent exceeded the DPPH of the TPC via the $100 \mathrm{WA}$ and $50 \mathrm{ETH}$ solvents, in accordance with the TPC concentrations recorded. Crucially, the lower temperature requirement when $65 \mathrm{ACE}$ is used may be translated to lower energy requirement and indeed improved economics in largescale processes. The information presented in the study may also enhance the future designing and optimizing extraction processes and reduction of scaling-up costs.

\section{Abbreviations}

TPC: Total phenolic compounds; AP: Apple pomace; GAE: Gallic acid equivalent; GHG: Greenhouse gas; DPPH: 2,2-Diphenyl-1 picrylhydrazyl; WAP: Waste apple pomace; 100 WA: Water-only; 50 ETH: 50\% Ethanol-50\% water v/v; 65 ACE: $65 \%$ Acetone-35\% water v/v.

\section{Supplementary Information}

The online version contains supplementary material available at https://doi. org/10.1186/s40643-021-00465-4.

Additional file 1. Statistical significance of process variables of temperature and time on total polyphenol (TPC) extraction.

\section{Acknowledgements}

We acknowledge Materne-Confilux Company for providing waste apple pomace for our experimental investigation. O.V.O. gratefully acknowledges the financial support of Wallonia-Brussels International via the Wallonie-Bruxelles International (WBI) excellence Postdoctoral fellowship.

\section{Authors' contributions}

$\mathrm{PH}$ : data collection, experimental investigation, writing-original draft. OVO: conceptualization, writing - original draft. AS: conceptualization, supervision, review. CD: writing, review and editing. $H A$, DP, KVB: formal analysis, review 
and editing. LN: validation, review and editing. All authors read and approved the final manuscript.

\section{Funding}

This research received no external funding.

Availability of data and materials

All the needed data are provided in the manuscript.

\section{Declarations}

Ethics approval and consent to participate

Not applicable.

\section{Consent for publication}

Not applicable.

\section{Competing interests}

The authors declare no conflict of interest in this study.

\section{Author details}

${ }^{1}$ Université Libre de Bruxelles (ULB), École polytechnique de Bruxelles - BioMatter unit, Avenue F.D. Roosevelt, 50 - CP 165/61, 1050 Brussels, Belgium. ${ }^{2}$ Laboratory of Pathophysiological and Nutritional Biochemistry, Université Libre de Bruxelles, Brussels, Belgium. ${ }^{3}$ School of Biomedical Sciences, University of Otago, Dunedin, New Zealand. ${ }^{4}$ Department of Process Engineering and Technology of Polymer and Carbon Materials, Faculty of Chemistry, Wroclaw University of Science and Technology, Norwida 4/6, 50-373 Wroclaw, Poland. ${ }^{5}$ College of Life Sciences, Xinyang Normal University (XYNU), Xinyang 464000, China. ${ }^{6}$ Faculty of Science and Engineering, Brightlands Chemelot Campus, Aachen-Maastricht Institute for Biobased Materials (AMIBM), Maastricht University, Urmonderbaan 22, 6167 RD Geleen, the Netherlands.

Received: 19 August 2021 Accepted: 31 October 2021

Published online: 24 November 2021

\section{References}

Alongi M, Melchior S, Anese M (2019) Reducing the glycemic index of short dough biscuits by using apple pomace as a functional ingredient. LWT 100:300-305. https://doi.org/10.1016/j.lwt.2018.10.068

Antonic B, Jancikova S, Dordevic D, Tremlova B (2020) Apple pomace as food fortification ingredient: a systematic review and meta-analysis. J Food Sci 85(10):2977-2985. https://doi.org/10.1111/1750-3841.15449

AOAC (1998). Combustion method for determination of crude protein in animal feeds, oilseed meals and oilseeds

ASTM (1998). D2017 - 98 Standard Test Method of Accelerated Laboratory Test of Natural Decay Resistance of Woods, decay, evaluation, laboratory, natural, resistance and subjected to termite bioassay according to nochoice test procedure based upon AWPA E1-97 (AWPA, 1)

ASTM (2007). D3172-07 Standard practice for proximate analysis of coal and coke

ASTM (2011). Standard test method for volatile matter in the analysis sample of coal and coke

ASTM (2015). Standard test method for determination of total solids in biomass. ASTM International

Bai X, Zhang H, Ren S (2013) Antioxidant activity and HPLC analysis of polyphenol-enriched extracts from industrial apple pomace. J Sci Food Agric 93(10):2502-2506. https://doi.org/10.1002/jsfa.6066

Balyan U, Sarkar B (2016) Aqueous extraction kinetics of phenolic compounds from jamun (Syzygium cumini L.) seeds. Int J Food Prop 20(2):372-389. https://doi.org/10.1080/10942912.2016.1163266

Bhushan S, Kalia K, Sharma M, Singh B, Ahuja PS (2008) Processing of apple pomace for bioactive molecules. Crit Rev Biotechnol 28(4):285-296. https://doi.org/10.1080/07388550802368895

Bucic-Kojic A, Sovova H, Planinic M, Tomas S (2013) Temperature-dependent kinetics of grape seed phenolic compounds extraction: experiment and model. Food Chem 136(3-4):1136-1140. https://doi.org/10.1016/j.foodc hem.2012.09.087

Candrawinata VI, Golding JB, Roach PD, Stathopoulos CE (2014) Optimisation of the phenolic content and antioxidant activity of apple pomace aqueous extracts. CyTA - J Food 13(2):293-299. https://doi.org/10.1080/19476 337.2014.971344

Carrier M, Loppinet-Serani A, Denux D, Lasnier J-M, Ham-Pichavant F, Cansell F, Aymonier C (2011) Thermogravimetric analysis as a new method to determine the lignocellulosic composition of biomass. Biomass Bioenergy 35(1):298-307. https://doi.org/10.1016/j.biombioe.2010.08.067

Cavdarova M, Makris DP (2014) Extraction kinetics of phenolics from Carob (Ceratonia siliqua L.) Kibbles using environmentally benign solvents. Waste Biomass Valorization 5(5):773-779. https://doi.org/10.1007/ s12649-014-9298-3

de Torre MP, Cavero RY, Calvo MI, Vizmanos UL (2019) A simple and a reliable method to quantify antioxidant activity in vivo. Antioxidants. https://doi. org/10.3390/antiox8050142

Diaconeasa Z (2018) Time-dependent degradation of polyphenols from thermally-processed berries and their in vitro antiproliferative effects against melanoma. Molecules 23(10):2534. https://doi.org/10.3390/molec ules 23102534

Gonzalez-Centeno MR, Comas-Serra F, Femenia A, Rossello C, Simal S (2015) Effect of power ultrasound application on aqueous extraction of phenolic compounds and antioxidant capacity from grape pomace (Vitis vinifera L.): experimental kinetics and modeling. Ultrason Sonochem 22:506-514. https://doi.org/10.1016/j.ultsonch.2014.05.027

Gowman AC, Picard MC, Rodriguez-Uribe A, Misra M, Khalil H, Thimmanagari M, Mohanty AK (2019) Physicochemical analysis of apple and grape pomaces. BioResources 14(2):3210-3230

Guerrero MRB, da Silva M, Paula M, Zaragoza MM, Gutiérrez JS, Velderrain VG, Ortiz AL, Collins-Martínez V (2014) Thermogravimetric study on the pyrolysis kinetics of apple pomace as waste biomass. Int J Hydrogen Energy 39(29):16619-16627. https://doi.org/10.1016/j.ijhydene.2014.06.012

Harouna-Oumarou HA, Fauduet H, Porte C, Ho Y-S (2007) Comparison of kinetic models for the aqueous solid-liquid extraction of tilia sapwood in a continuous stirred tank reactor. Chem Eng Commun 194(4):537-552. https://doi.org/10.1080/00986440600992511

Ibrahim S, Santos R, Bowra S (2019) Optimisation of organic solvent mediated solubilisation of apple pomace polyphenolic compounds using response surface methodologies. Int J Chem. https://doi.org/10.5539/ijc.v1 1n2p1

Jurinjak Tušek A, Benković M, Belščak Cvitanović A, Valinger D, Jurina T, Gajdoš Kljusurić J (2016) Kinetics and thermodynamics of the solid-liquid extraction process of total polyphenols, antioxidants and extraction yield from Asteraceae plants. Ind Crops Prod 91:205-214. https://doi.org/10.1016/j. indcrop.2016.07.015

Kim, J., Choi, K., \& Chung, D. S. (2012). 3.35 - Sample Preparation for Capillary Electrophoretic Applications. In J. Pawliszyn (Ed.), Comprehensive Sampling and Sample Preparation (pp. 701-721). Academic Press. https://doi. org/10.1016/B978-0-12-381373-2.00110-1

Lazar L, Talmaciu AI, Volf I, Popa VI (2016) Kinetic modeling of the ultrasoundassisted extraction of polyphenols from Picea abies bark. Ultrason Sonochem 32:191-197. https://doi.org/10.1016/j.ultsonch.2016.03.009

Li W, Yang R, Ying D, Yu J, Sanguansri L, Augustin MA (2020) Analysis of polyphenols in apple pomace: a comparative study of different extraction and hydrolysis procedures. Ind Crops Prod. https://doi.org/10.1016/j.inder op.2020.112250

Lu Y, Foo LY (2000) Antioxidant and radical scavenging activities of polyphenols from apple pomace. Food Chem 68(1):81-85. https://doi.org/10. 1016/S0308-8146(99)00167-3

Lyu F, Luiz SF, Azeredo DRP, Cruz AG, Ajlouni S, Ranadheera CS (2020a) Apple pomace as a functional and healthy ingredient in food products: a review. Processes. https://doi.org/10.3390/pr8030319

Lyu F, Luiz SF, Azeredo DRP, Cruz AG, Ajlouni S, Ranadheera CS (2020b) Apple pomace as a functional and healthy ingredient in food products: a review. Processes 8(3):319

Makris DP, Kefalas P (2015) Kinetic modelling for polyphenol extraction from onion (Allium cepa) solid wastes using acidified water/ethanol mixture. Acta Aliment 44(4):482-492. https://doi.org/10.1556/066.2015.44.0020

Mokrani A, Madani K (2016) Effect of solvent, time and temperature on the extraction of phenolic compounds and antioxidant capacity of peach 
(Prunus persica L.) fruit. Sep Purif Technol 162:68-76. https://doi.org/10. 1016/j.seppur.2016.01.043

Narayana Namasivayam S, Bee Lin C, Yen Leng C, Hosseini Fouladi M, Eunice Phang SW, Chua BL, Chow YH, Yong LC, Al-Obaidi ASM (2018) Solid-liquid extraction kinetics of total phenolic compounds (TPC) from red dates. MATEC Web of Conferences. https://doi.org/10.1051/matecconf/20181 5201001

Okoro OV, Shavandi A (2021) An assessment of the utilization of waste apple slurry in bio-succinic acid and bioenergy production. Int J Environ Sci Technol. https://doi.org/10.1007/s13762-021-03235-z

Okoro OV, Nie L, Hobbi P, Shavandi A (2021) Valorization of waste apple pomace for production of platform biochemicals: a multi-objective optimization study. Waste Biomass Valorization. https://doi.org/10.1007/ s12649-021-01487-x

Okoro OV, Sun Z, Birch J (2017) Meat processing waste as a potential feedstock for biochemicals and biofuels - a review of possible conversion technologies. J Clean Prod 142:1583-1608. https://doi.org/10.1016/j.jclepro. 2016.11.141

Okoro OV, Sun Z, Birch J (2018) Prognostic assessment of the viability of hydrothermal liquefaction as a post-resource recovery step after enhanced biomethane generation using co-digestion technologies. Appl Sci 8(11):2290

Perussello CA, Zhang Z, Marzocchella A, Tiwari BK (2017) Valorization of apple pomace by extraction of valuable compounds. Compr Rev Food Sci Food Saf 16(5):776-796. https://doi.org/10.1111/1541-4337.12290

Pingret D, Fabiano-Tixier A-S, Bourvellec CL, Renard CMGC, Chemat F (2012) Lab and pilot-scale ultrasound-assisted water extraction of polyphenols from apple pomace. J Food Eng 111(1):73-81. https://doi.org/10.1016/j. jfoodeng.2012.01.026

Qu W, Pan Z, Ma H (2010) Extraction modeling and activities of antioxidants from pomegranate marc. J Food Eng 99(1):16-23. https://doi.org/10. 1016/j.jfoodeng.2010.01.020
Reis SF, Rai DK, Abu-Ghannam N (2012) Water at room temperature as a solvent for the extraction of apple pomace phenolic compounds. Food Chem 135(3):1991-1998. https://doi.org/10.1016/j.foodchem.2012.06.068 Rodriguez De Luna SL, Ramirez-Garza RE, Serna Saldivar SO (2020) Environmentally friendly methods for flavonoid extraction from plant material: impact of their operating conditions on yield and antioxidant properties. ScientificWorldJournal 2020:6792069. https://doi.org/10.1155/2020/ 6792069

Shavandi A, Bekhit AEA, Saeedi P, Izadifar Z, Bekhit AA, Khademhosseini A (2018) Polyphenol uses in biomaterials engineering. Biomaterials 167:91-106. https://doi.org/10.1016/j.biomaterials.2018.03.018

Shewale S, Rathod VK (2018) Extraction of total phenolic content from Azadirachta indica or (neem) leaves: Kinetics study. Prep Biochem Biotechnol 48(4):312-320. https://doi.org/10.1080/10826068.2018.1431784

Vidović, S., Tepić Horecki, A., Vladić, J., Šumić, Z., Gavarić, A., \& Vakula, A. (2020). Chap - Apple. In C. M. Galanakis (Ed.), Valorization of Fruit Processing By-products. Cambridge: Academic Press, 17-42. https://doi.org/10.1016/ B978-0-12-817106-6.00002-2

Wijngaard HH, Brunton N (2010) The optimisation of solid-liquid extraction of antioxidants from apple pomace by response surface methodology. J Food Eng 96(1):134-140. https://doi.org/10.1016/j.jfoodeng.2009.07.010

Zardo DM, Alberti A, Zielinski AAF, Prestes AA, Esmerino LA, Nogueira A (2020) Influence of solvents in the extraction of phenolic compounds with antibacterial activity from apple pomace. Sep Sci Technol 56(5):903-911. https://doi.org/10.1080/01496395.2020.1744652

\section{Publisher's Note}

Springer Nature remains neutral with regard to jurisdictional claims in published maps and institutional affiliations.

\section{Submit your manuscript to a SpringerOpen ${ }^{\odot}$ journal and benefit from:}

- Convenient online submission

- Rigorous peer review

- Open access: articles freely available online

- High visibility within the field

- Retaining the copyright to your article

Submit your next manuscript at $\boldsymbol{\nabla}$ springeropen.com 